\title{
The Characteristics of Ubiquitous and Unique Leptospira Strains from the Collection of Russian Centre for Leptospirosis
}

\author{
Olga L. Voronina, Marina S. Kunda, Ekaterina I. Aksenova, Natalia N. Ryzhova, \\ Andrey N. Semenov, Evgeny M. Petrov, Lubov V. Didenko, Vladimir G. Lunin, \\ Yuliya V. Ananyina, and Alexandr L. Gintsburg
}

\begin{abstract}
N.F. Gamaleya Institute for Epidemiology and Microbiology, Ministry of Health of Russia, Gamaleya Street 18, Moscow 123098, Russia
\end{abstract}

Correspondence should be addressed to Olga L. Voronina; kirolg3@newmail.ru

Received 22 May 2014; Revised 29 July 2014; Accepted 5 August 2014; Published 2 September 2014

Academic Editor: Vassily Lyubetsky

Copyright (C) 2014 Olga L. Voronina et al. This is an open access article distributed under the Creative Commons Attribution License, which permits unrestricted use, distribution, and reproduction in any medium, provided the original work is properly cited.

\begin{abstract}
Background and Aim. Leptospira, the causal agent of leptospirosis, has been isolated from the environment, patients, and wide spectrum of animals in Russia. However, the genetic diversity of Leptospira in natural and anthropurgic foci was not clearly defined. Methods. The recent MLST scheme was used for the analysis of seven pathogenic species. 454 pyrosequencing technology was the base of the whole genome sequencing (WGS). Results. The most wide spread and prevalent Leptospira species in Russia were L. interrogans, L. kirschneri, and L. borgpetersenii. Five STs, common for Russian strains: 37, 17, 199, 110, and 146, were identified as having a longtime and ubiquitous distribution in various geographic areas. Unexpected properties were revealed for the environmental Leptospira strain Bairam-Ali. WGS of this strain genome suggested that it combined the features of the pathogenic and nonpathogenic strains and may be a reservoir of the natural resistance genes. Results of the comparative analysis of rrs and rpoB genes and MLST loci for different Leptospira species strains and phenotypic and serological properties of the strain Bairam-Ali suggested that it represented separate Leptospira species. Conclusions. Thus, the natural and anthropurgic foci supported ubiquitous Leptospira species and the pool of genes important for bacterial adaptivity to various conditions.
\end{abstract}

\section{Introduction}

Leptospira is a genus of bacteria that is encountered in all geographical areas, except arctic and arid regions. Some Leptospira are responsible for leptospirosis, a natural-focus disease. According to the List of Prokaryotic names with Standing in Nomenclature, the Leptospira genus has 21 species [1]. Seven of the species have been established as pathogenic: L. interrogans, L. borgpetersenii, L. kirschneri, L. noguchii, $L$. santarosai, $L$. weilii, and $L$. alexanderi. Two species, $L$. alstonii and L. kmetyi, are candidates for assignment to the pathogenic group; they are rarely isolated, and the sources of their isolation are not ill humans. L. alstonii was isolated from a frog and L. kmetyi was isolated from soil. Phylogenetic analysis with $16 \mathrm{~S}$ rRNA gene sequences showed that $L$. alstonii and L. kmetyi clustered with the pathogenic Leptospira species $[2,3]$. Five species, $L$. broomii, L. fainei, L. inadai,
L. licerasiae, and $L$. wolffi, are classified as intermediate, and six species, $L$. biflexa, $L$. meyeri, $L$. terpstrae, $L$. vanthielii, $L$. wolbachii, and L. yanagawae, are nonpathogenic [4]. One new species, $L$. idonii, isolated from the environmental water, is candidate for assignment to the nonpathogenic group. This species is placed within the clade of the known saprophytic species of the genus Leptospira on the 16S rRNA gene-based phylogenetic analysis [5].

According to WHO guidance [6], the incidence of leptospirosis ranges from about $0.1-1$ per 100000 persons per year in temperate climates to $10-100$ per 100000 in the humid tropics. In the Russian Federation, only 0.01 cases per 100000 were reported in 2013. During 2012-2013, 506 cases were registered in Russia according to the report of the Federal Service for Supervision of Consumer Rights Protection and Human Welfare (http://rospotrebnadzor.ru/). Long-term control of the multiple natural and anthropurgic 
foci in the USSR has been organized with the participation of the MoH Centre for Leptospirosis, an action which may be responsible for the decrease in incidence. During the registration period, strains of Leptospira species were isolated, from the animals (maintenance and supplementary hosts of the Leptospira), human patients, and environment, and saved in the Gamaleya Institute Microbial Collection (GIMC).

Among the strains of Leptospira species in GIMC one strain was mysterious and not closely related to any Leptospira, either pathogenic or saprophytic; it was named Leptospira spp. strain Bairam-Ali. Bairam-Ali was isolated from the water of a drainage canal in Turkmenia in 1971. On the basis of phenotypic tests, it was classified as a saprophytic species, although its resistance to the leptospiracidal activity of normal mammal sera and some other features made it closer to the pathogenic leptospires. Thus, Leptospira sp. strain Bairam-Ali was used in a diagnostic system on the basis of macroagglutination reaction. This diagnostic system was different from the original genus-specific microagglutination test, which requires multiple serovars of live Leptospira and involves a risk of infection. Strain Bairam-Ali is a natural substitute for the microcapsule of synthetic polymer [7] as carrier of antigens similar to pathogenic strains, and it is safe for humans.

Only whole genome sequence could help resolve the mystery of the strain Bairam-Ali and clarify its phylogenetic position in the Leptospira genus and relationships with the pathogenic Leptospira species.

\section{Materials and Methods}

2.1. Bacterial Strains. Leptospira strains were cultured by the Russian $\mathrm{MoH}$ Centre for Leptospirosis laboratory at the N.F. Gamaleya Institute for Epidemiology and Microbiology, Moscow, according to WHO guidance [6]. Fifty-eight strains, including 29 reference strains and 29 isolates from various sources and geographical regions, were analyzed. Twenty-six reference strains were members of seven pathogenic species. By the start of this study, seven reference strains were absent from the Leptospira MLST database [8].

2.2. Phenotypic and Serological Characterization of Strain Bairam-Ali. Methods for differentiation of pathogenic versus saprophytic strains and for cross-agglutination-absorption reactions were performed according to WHO guidance [6].

2.3. Scanning Electron Microscopy. Samples were prepared as described in detail [9] and analyzed with dual-beam focused ion beam/scanning electron microscope, Quanta 200 3D (FEI Company, USA), in both high and low vacuum, mostly at $5 \mathrm{kV}$ electron beam acceleration [10].

2.4. DNA Isolation. DNA for PCR analysis was extracted from the bacterial cultures as described previously [11]. Preparation of genomic DNA for the whole genome sequencing was performed according to [12].
2.5. Leptospira Species Identification. The species of isolates were identified by amplification and sequencing of the $r p o B$ gene (coding $\beta$ subunit of bacterial RNA polymerase), according to La Scola et al. [13]. Sequence data for $r p o B$ has been deposited in GenBank, with accession numbers KJ701730-KJ701749.

2.6. MLST. MLST for the strains of $L$. interrogans and $L$. kirschneri was performed by use of the original scheme of Thaipadungpanit et al. [14]. After publication of the modified MLST scheme [15], we completed earlier results by using $c a i B$ gene sequences. For the new isolates and strains of five other species, we used only the modified MLST scheme. Some modifications were inserted in the published protocol. The conditions of the amplification were modified for the $g \operatorname{lm} U$, $p n t A$, and sucA genes by raising the melting temperature to $50^{\circ} \mathrm{C}$. Also, the $\mathrm{MgCl}_{2}$ concentration was changed to $3.5 \mathrm{mM}$ for the $g \operatorname{lm} U$, $p n t A$, and $s u c A$ genes. Reference collection strains were used for adaptation of the method to our laboratory and for control of the reproducibility of the results.

2.7. PCR Products Sequencing. PCR products were sequenced according to the protocol of BigDye Terminator 3.1 Cycle Sequencing kit for the Genetic Analyzer 3130 of Applied Biosystems/Hitachi.

2.8. Nucleotide Sequence Analysis. The alignment of $r p o B$ and MLST gene sequences was made by use of ClustalW2 [16]. BLAST search was used for species identification; similarity of $r p o B$ gene sequences was more than $98 \%$.

Allele numbers for MLST genes were assigned with the help of website MLST Home. Allelic profiles, in the order glmU-pntA-sucA-tpiA-pfkB-mreA-caiB, were used to assign sequence types (STs) to strains. New alleles and ST were controlled and submitted by the curator of Leptospira spp. MLST database [8]. All new Leptospira strains were submitted in the Leptospira spp. MLST database under the identification numbers indicated in Table 1.

Relatedness between STs on the base of allelic profiles was analyzed by use of BURST version $1.00[17,18]$.

2.9. Nucleotide Sequence Polymorphism. BLAST search was used for retrieving homologues rrs (16S rRNAcoding), $r p o B$, and MLST gene sequences from GenBank (http://www.ncbi.nlm.nih.gov/genome/browse/). For comparative sequence analysis and phylogenetic reconstruction, nucleotide sequences of 92 additional Leptospira strains were retrieved. Seventy-five nucleotide sequences represented either complete or partial cds of rrs gene and rpoB gene, and 15 sequences represented whole genome sequencing data and genome drafts (Table 1). Turneriella parva have been included in the analysis as an out-group taxon from Leptospiraceae, for which whole genome sequence data are available (Table 1). Sequences of seven concatenated MLST loci for 201 ST available at the time of analysis were retrieved [8]. The alignments of $r r s$, $r p o B$, and MLST gene sequences and analysis nucleotide similarity (in \%) were performed by use of ClustalW2 [16]. 


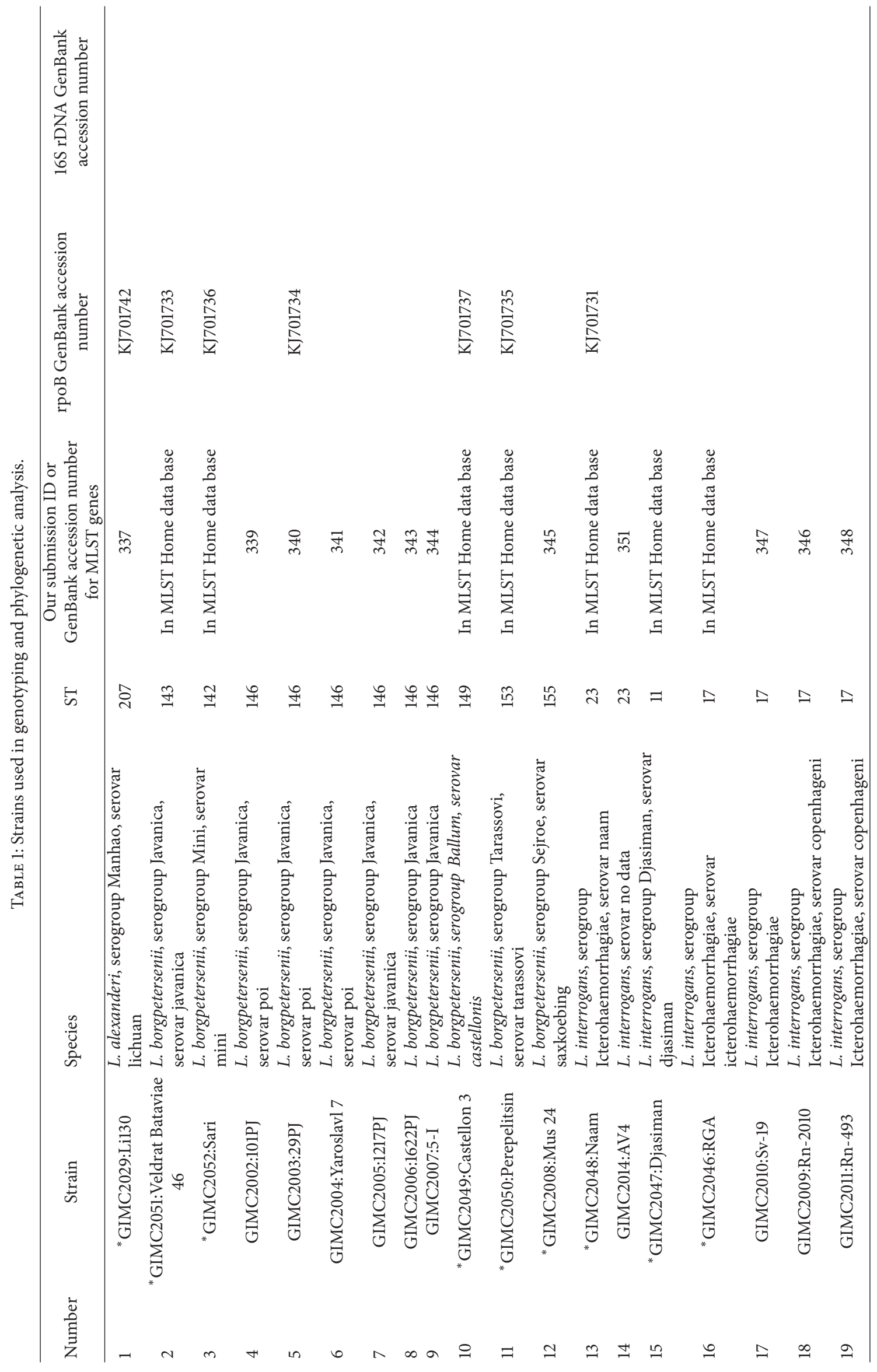




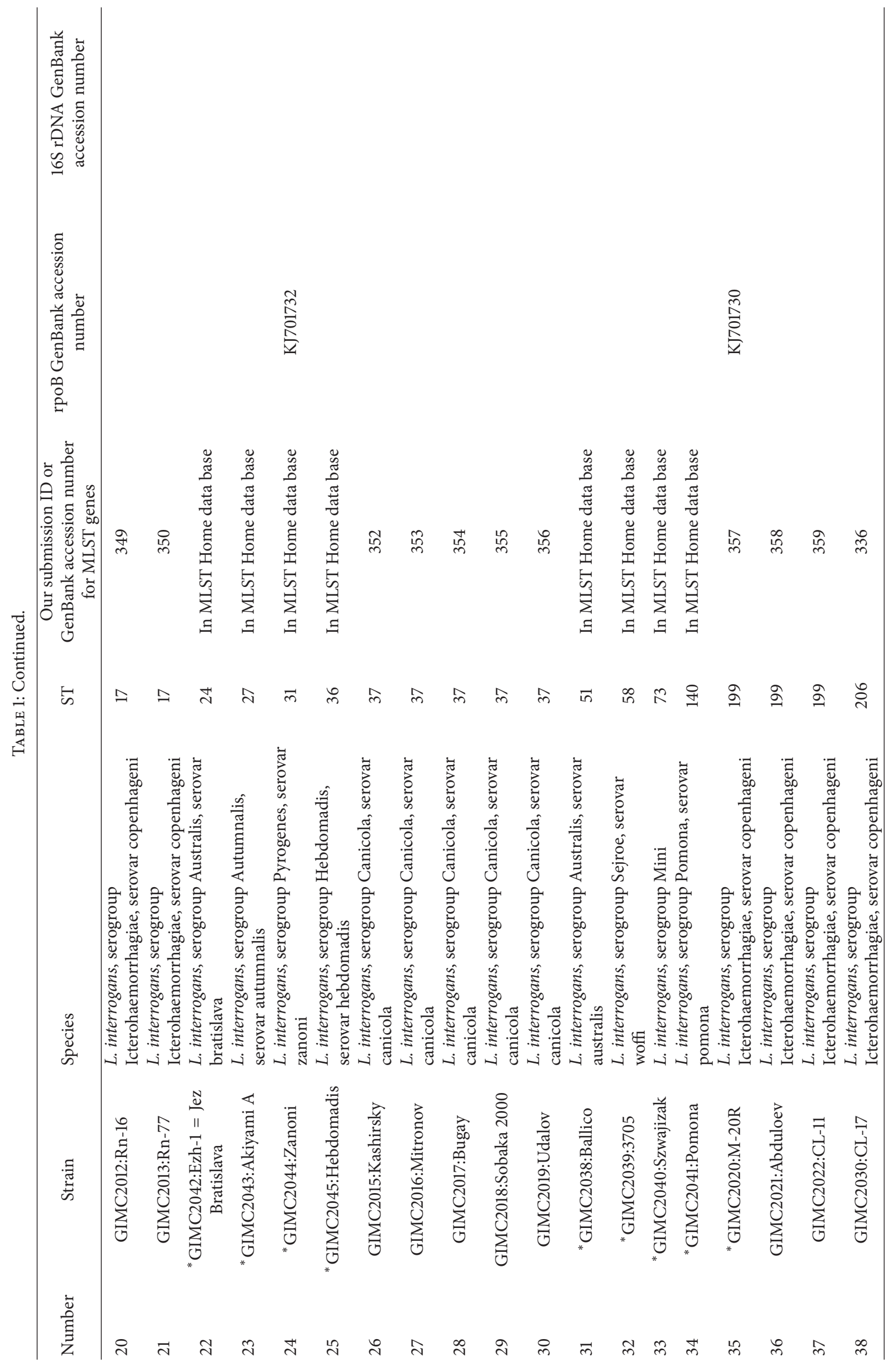




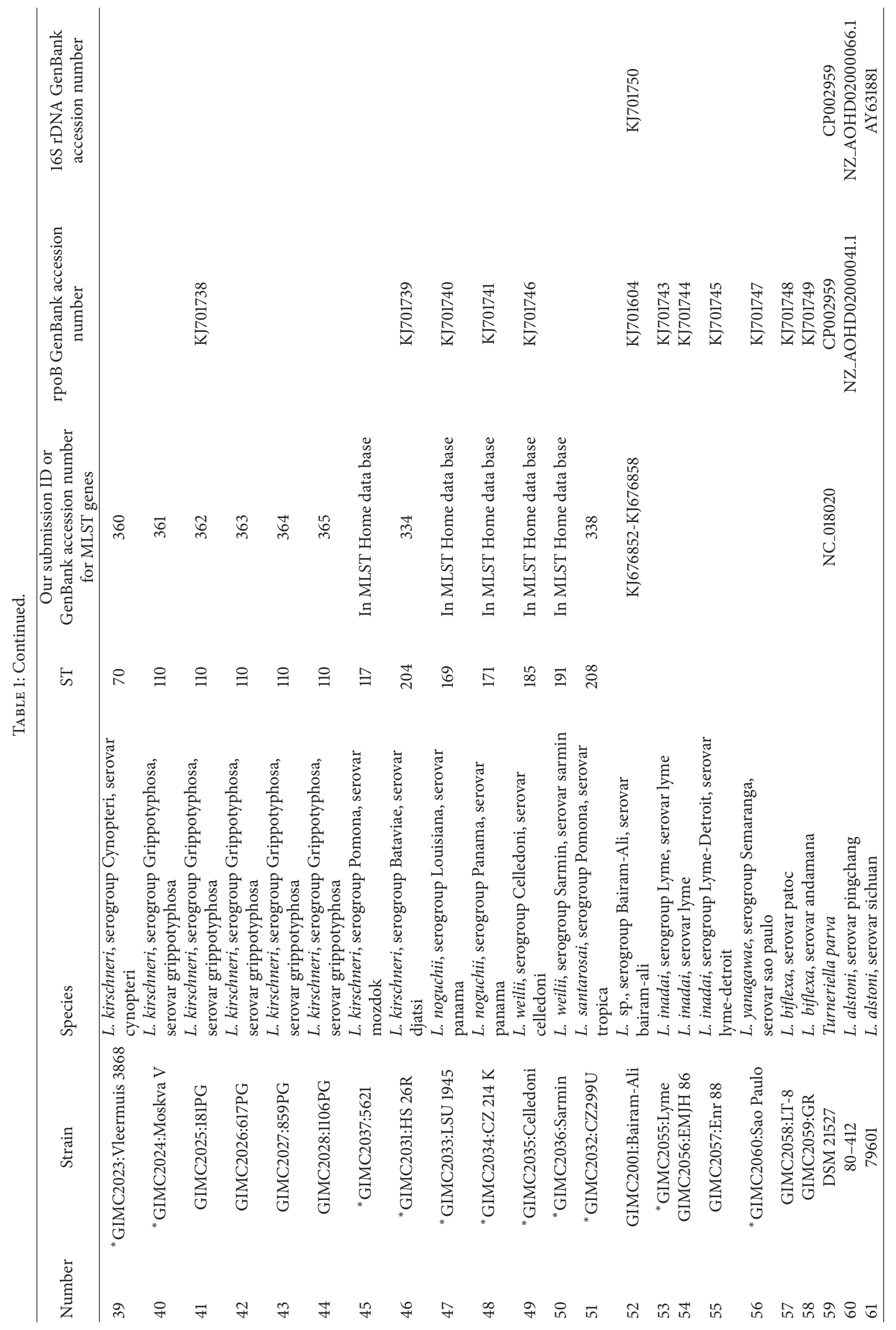




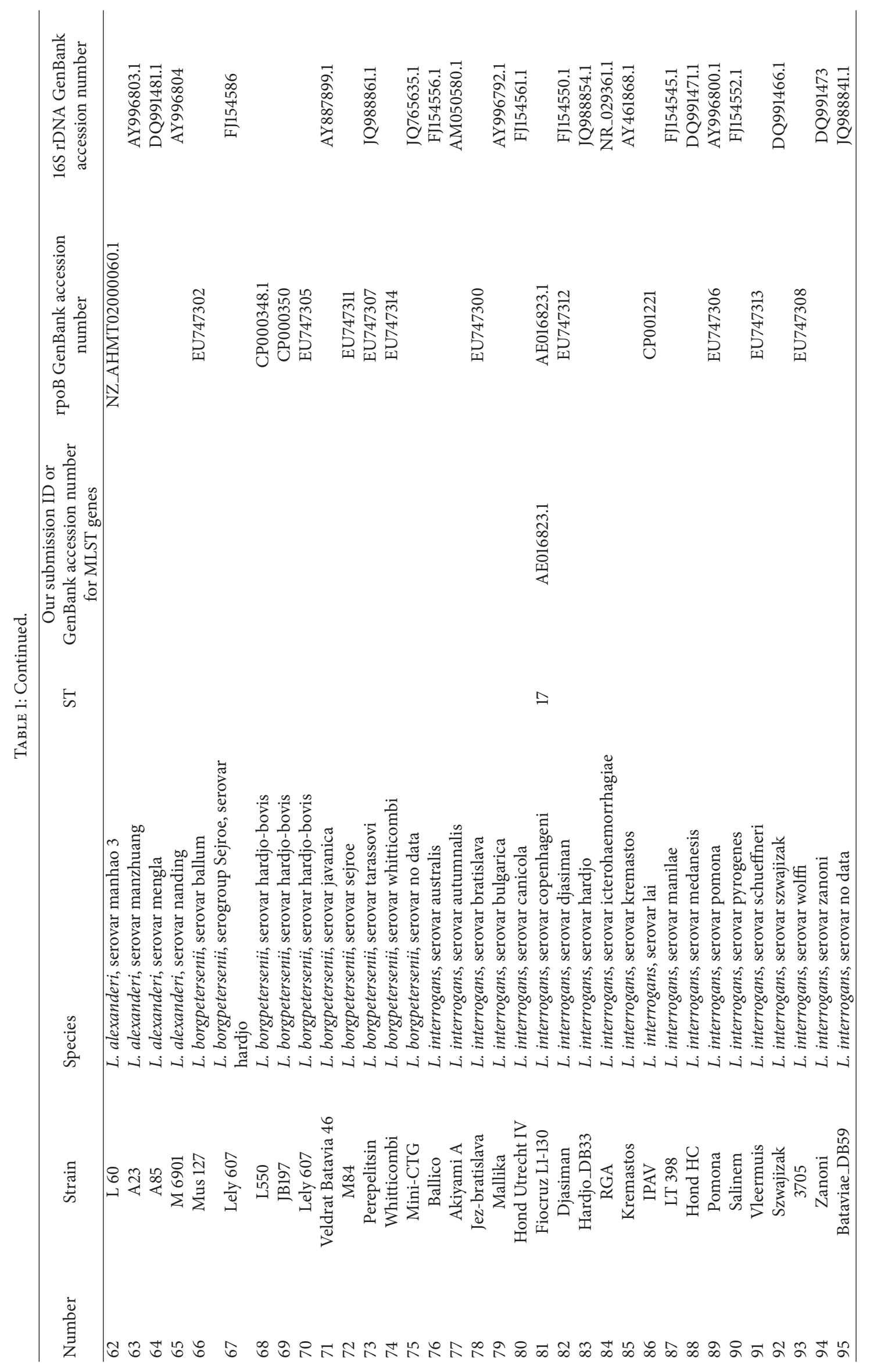




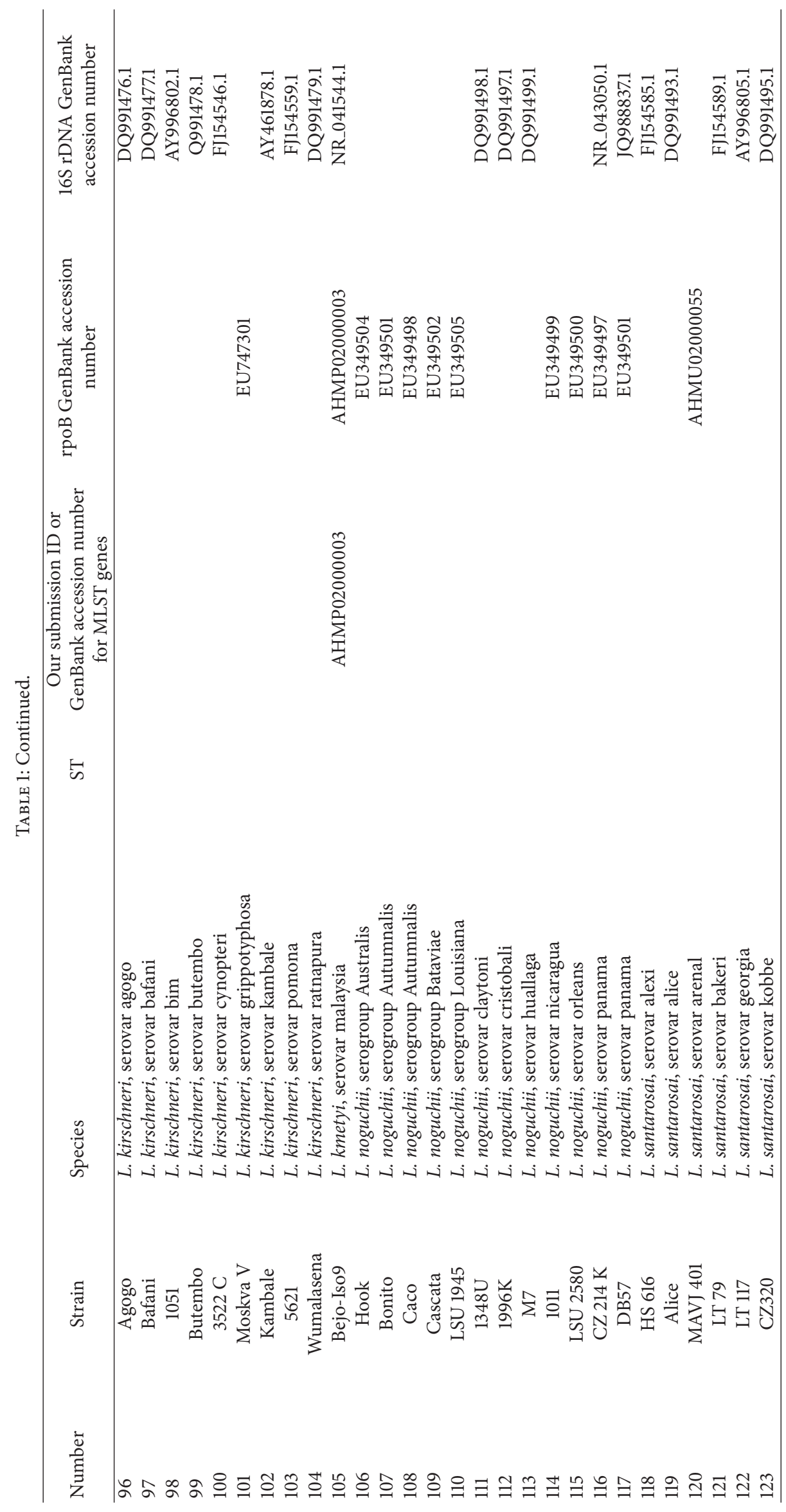




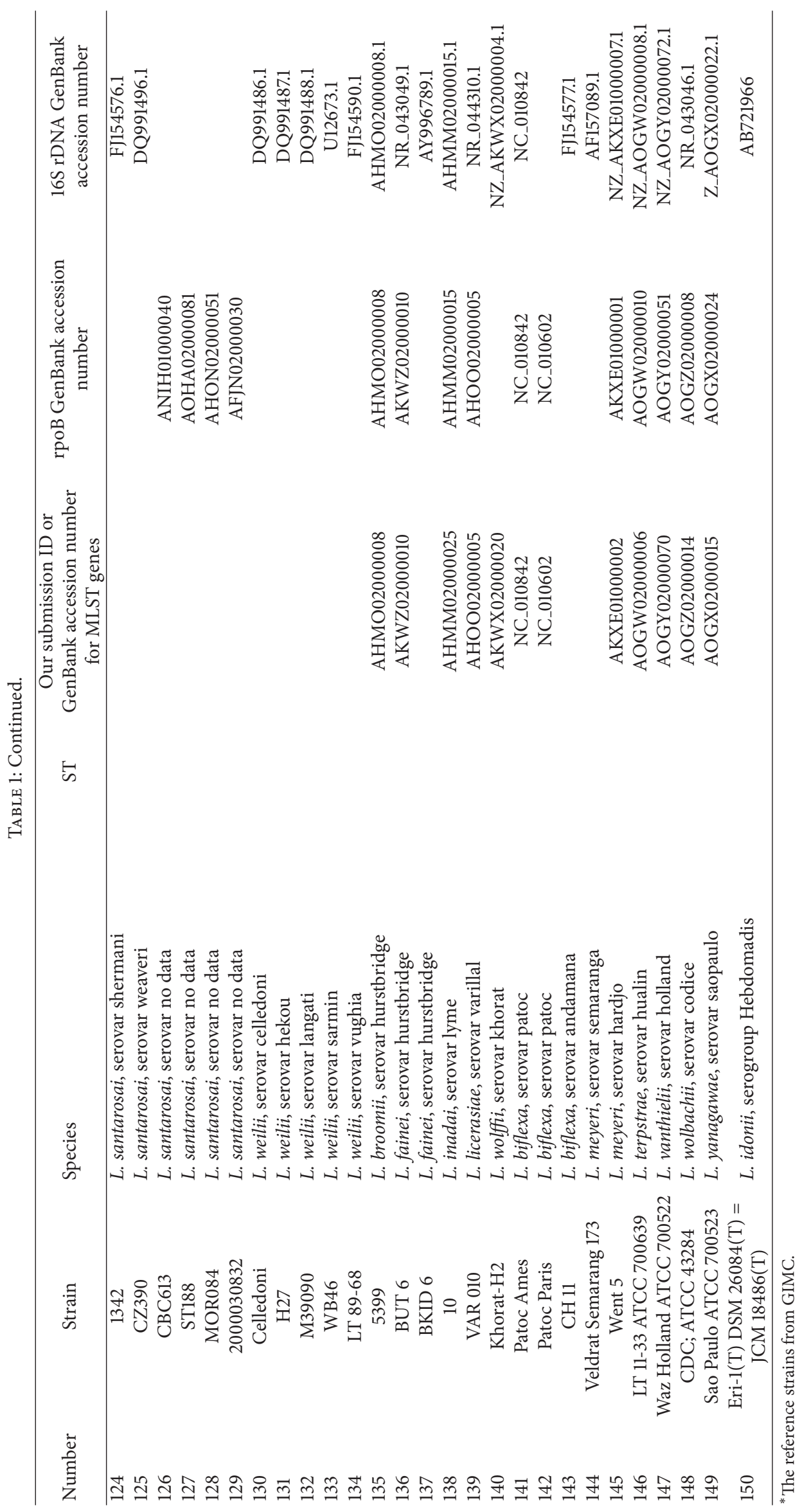


2.10. Phylogenetic Analysis. Phylogenetic analysis of Leptospira species was performed based on the rrs gene fragment, $r p o B$ gene fragment, and seven concatenated sequences of MLST loci. Phylogenetic trees were constructed by use of neighbor-joining, maximum likelihood, and maximum parsimony methods.

Genetic distances between Leptospira genotypes were evaluated by use of Kimura's two-parameter model [19], which was chosen as an optimal evolution distance model derived from model test based on the Akaike information criterion [20]. The evolutionary history was inferred by using the Maximum Likelihood method based on the general time reversible model [21]. Initial tree(s) for the heuristic search were obtained automatically by applying neighbor-joining and BioNJ algorithms to a matrix of pairwise distances estimated by use of the maximum composite likelihood approach and then selecting the topology with superior log likelihood value. A discrete gamma distribution was used to model evolutionary rate differences among sites (six categories $(+\mathrm{G}$, parameter $=0.4818)$ ). Maximum parsimony trees were constructed with an algorithm implemented in MEGA version 6.0 [22]. Bootstrap analyses were performed with 1,000 replicates.

2.11. Whole Genome Sequencing. Whole genome sequencing of Leptospira spp. strain GIMC2001:Bairam-Ali was performed according to the manufacturer's guidelines (Roche) for the next generation sequencing (NGS). Two protocols were used for a shotgun-sequencing library preparation: rapid library and pair-end library. The rapid library was made according to the Rapid Library Preparation Method Manual (Roche). The pair-end library was performed according to the $3 \mathrm{~kb}$ protocol provided by the manufacturer to aid in scaffold building. The paired-end library insert size was from 1347 to $4364 \mathrm{bp}$, with an average of $2695 \mathrm{bp}$.

Assembly was performed with 454 Sequencing System Software v.2.7 (Roche), yielding 14 scaffolds, with the largest size being $3342467 \mathrm{bp}$. Gap closure was performed by use of Contig Graph result file generated by GS De Novo Assembler program (Roche). For the oriC region search, Ori-Finder program was used [23].

2.12. Gene Annotation. The software Rapid Annotations Subsystems Technology and SEED [24, 25] were used for annotating the genome of Leptospira spp. strain GIMC2001:BairamAli.

\section{Results and Discussion}

A sample of the collection (GIMC) of the Russian $\mathrm{MoH}$ Centre for Leptospirosis was used for the verification the species and strains based on the currently recommended molecular-genetic methods. The sample included 29 reference strains and 29 isolates of Leptospira from various geographical regions (Table $1,{ }^{*}$-marker of the reference strains from GIMC).

The analysis of $r p o B$ gene sequences demonstrated that 29 reference strains belonged to seven pathogenic species, one nonpathogenic species (L. yanagawae), and one intermediate species (L. inadai). Among 29 isolates of Leptospira twenty-four field isolates were related to the three pathogenic species (L. interrogans, L. borgpetersenii, and L. kirschneri). Four cultures were isolated from the commercially available Ellinghausen-McCullough-JohnsonHarris (EMJH) medium: two isolates from this group belonged to the nonpathogenic species $L$. biflexa and the other two isolates belonged to the intermediate species L. inadai. Thus, the prevailing species among the isolates collected on the territory of Russia comprised L. interrogans, L. borgpetersenii, and L. kirschneri.

The modified MLST scheme was applied to the isolates and reference strains representing 7 pathogenic Leptospira species. Twenty-four isolates of pathogenic species belonged to 8 different STs (Table 1). Five STs, common for Russian strains of Leptospira (L. interrogans ST37, 17, and 199; L. kirschneri ST110; and L. borgpetersenii ST146), were identified as having a longtime and ubiquitous distribution in various geographic areas.

Among the strains of Leptospira species available in GIMC, one strain seemed to be mysterious and not closely related to any Leptospira, either pathogenic or saprophytic, or intermediate. It was named Leptospira spp. strain Bairam-Ali, because it was isolated in 1971 in Turkmenia from the water of a drainage canal.

3.1. Morphology of the Leptospira spp. Strain Bairam-Ali. The morphology of the mysterious strain Bairam-Ali is typical of that of the Leptospira genus (Figure 1). Electron microscopy demonstrated that its cells are corkscrew-shaped with end hooks. They are thin and helical, like the cells of all known leptospires. Also, the cells have a diameter $(d)$ of $0.12 \mu \mathrm{m}$ and length $(l)$ from 9.44 to $10.14 \mu \mathrm{m}$, like that of known leptospires $(d=0.15-0.3 \mu \mathrm{m}$ and $l=6,00-20,00 \mu \mathrm{m})$ [26].

3.2. Phenotypic Characterization of the Leptospira spp. Strain Bairam-Ali. Physiological characteristics of BairamAli, demonstrated in Table 2, suggest that strain Bairam-Ali can be classified as saprophytic Leptospira.

For pathogenicity experiment, six four-week-old male golden Syrian hamsters were inoculated subcutaneously with $10^{8}$ cells of strain Bairam-Ali in $1 \mathrm{~mL}$ of PBS. No hamster died from infection even at such a high bacterial dose. Leptospira cells were not detected during following bacterioscopic and bacteriological examination of the hamsters' viscera. This is an additional evidence of saprophytic quality of Bairam-Ali.

On the other hand, Bairam-Ali was resistant to the bactericidal (leptospiracidal) activity of the normal serum of human and of some other mammal animals. The most of pathogenic Leptospira species were resistant too, whereas the saprophytic species L. biflexa was sensitive.

3.3. Serological Characterization of the Leptospira spp. Strain Bairam-Ali. The strain Bairam-Ali had no antigenic affinity with 18 different serovars represented by reference strains. So the conclusion about the original serotype of Bairam-Ali was 


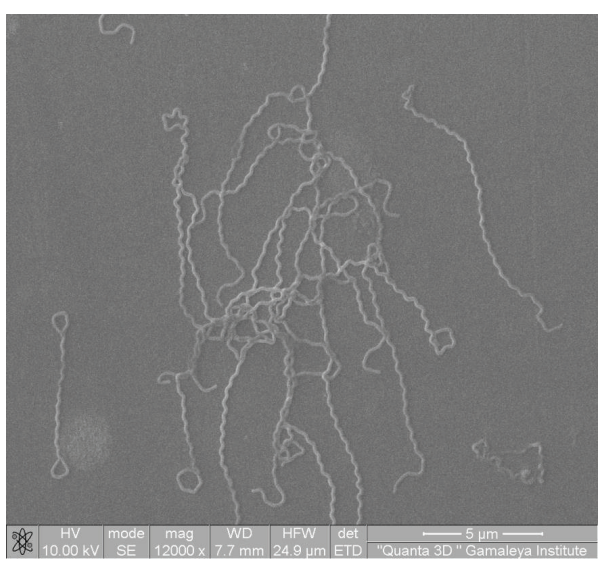

(a)

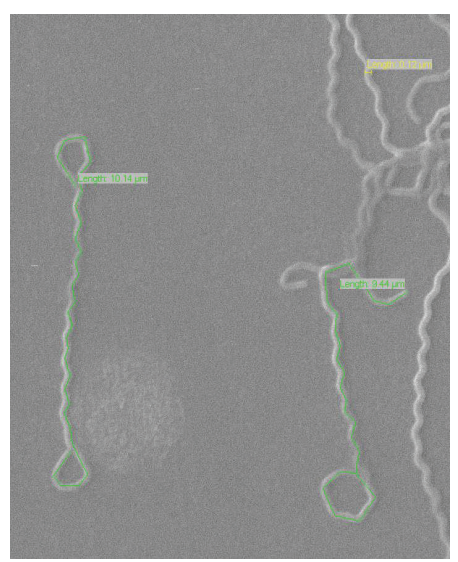

(b)

Figure 1: Dual-beam scanning electron microscopy image of $L$. species Bairam-Ali cells. (a) Original image; (b) with measuring the object in the program "Scandium" (green, length $10,14 \mu \mathrm{m}$; yellow, length (diameter) $0,12 \mu \mathrm{m}$; and green, length $9,44 \mu \mathrm{m}$ ).

TABle 2: Physiological characteristics of the Leptospira spp. strain Bairam-Ali.

\begin{tabular}{lcccccc}
\hline Strain & \multicolumn{2}{c}{ Growth at temp $\left({ }^{\circ} \mathrm{C}\right)$ of } & Growth in the presence of & Lipase activity & Hemolytic activity against sheep erythrocytes \\
& 11 & 30 & 37 & 8 -Azaguanine $225 \mathrm{pg} / \mathrm{mL}$ & + \\
\hline Bairam-Ali & + & + & + & + & + \\
\hline
\end{tabular}

made. The serovar of Bairam-Ali was named bairam-ali. It formed the separated serogroup Bairam-Ali.

3.4. The Whole Genome Sequence Analysis. The whole genome sequence could help to resolve the mystery of the strain Bairam-Ali and clarify its phylogenetic position in the Leptospira genus.

According to the NGS data the whole Bairam-Ali genome is $4,4 \mathrm{Mb}$, with GC \% 34,74 and two chromosomes. The first chromosome is $4059463 \mathrm{bp}$ and the second is $325649 \mathrm{bp}$. Plasmid, typical of nonpathogenic Leptospira species, was absent from the Bairam-Ali genome. On the base of genome size and GC content, demonstrated in Table 3, Bairam-Ali is more similar to the pathogenic species $L$. interrogans and $L$. noguchii.

Based on $r p o B$ gene sequence, we established that Bairam-Ali is more similar to pathogenic strain L. interrogans Fiocruz-L1-130 (but the level of similarity is only $70.00 \%$ ). However, by sequence of rDNA genes it is similar to nonpathogenic strains: for gene $r r s$, coding $16 \mathrm{~S}$ rRNA, L. meyeri was most closely related (92.74\%); for gene $r r l$, coding $23 \mathrm{~S}$ rDNA, L. biflexa was more similar $(95.00 \%$ fragment 1 and $93.00 \%$ fragment 2). Sequences of rDNA genes of BairamAli were deposited in GenBank, accession numbers KJ701750, KJ701751, and KJ701752.

These data suggest dual phenotypic characteristics of the strain Bairam-Ali. In spite of having differences from both pathogenic and nonpathogenic species, many of the functional categories that are involved in essential housekeeping functions are represented in its core gene $[27,28]$. Thus, basic groups of proteins involved in cell metabolism, survival, environmental adaptability, and potential pathogenic factors were
TABLE 3: Comparison L. spp. Bairam-Ali strain genome characteristics with most closely related Leptospira species.

\begin{tabular}{lcc}
\hline Leptospira strain or species & Genome size, Mbp & GC $\%$ \\
\hline L-BA $^{*}$ & 4,4 & 34,7 \\
L. interrogans & $4,56 \pm 0,32$ & $35,22 \pm 0,27$ \\
L. noguchii & $4,76 \pm 0,16$ & $35,63 \pm 0,27$ \\
L. terpstrae & 4,09 & 38,2 \\
L. meyeri & 4,15 & 38,05 \\
L. vanthielii & 4,23 & 38,9 \\
L. biflexa & 3,95 & 38,9 \\
\hline
\end{tabular}

${ }^{*}$ L-BA: Leptospira spp. Bairam-Ali.

present. Enzyme complexes participating in implementation of genetic information, in particular in DNA replication, were identified in strain Bairam-Ali: chromosomal replication initiator protein DNA, single-stranded DNA-binding protein; all subunits of DNA polymerase III, DNA polymerase I, and DNA polymerase IV; DNA gyrase; ligase; and helicase [29]. Also, the large groups of enzymes that take part in DNA reparation [29], for example, excinuclease ABC subunits A$\mathrm{C}$ and exodeoxyribonuclease (III, V, and VII), and proteins of postreplicative mismatch repair system (Mutator $S$ and Mutator L) were present. Archaeal DNA polymerase I gene was detected in the Bairam-Ali genome; this gene is a member of Family B and bacterial DNA polymerase II. The same gene was present in nonpathogenic strain L. biflexa Patoc genome but not in pathogenic L. interrogans Fiocruz-L1-130 and L. borgpetersenii Hardjo-bovis-L550 genomes [27, 30]. The sequences of DNA metabolome have been deposited in GenBank, with accession numbers KJ701710-KJ701729. 
According to Bourret et al. [31], enteric bacteria usually have about 50 genes coding for structural and functional proteins involved in motility. Motility is a distinctive feature of Leptospira; forty-seven different proteins provide bacterial locomotion [32]. In the Bairam-Ali genome, the genes for proteins of the basic parts of periplasmic flagella were detected: basal-body (Flg B-D, FlgF, and FlgG), hook (FlgE, FlgK, FlgL, FliE, FliD, and fliK), and four copies of FlaA (sheath protein of filament). The genes for proteins of flagellar rings $\mathrm{L}(\mathrm{FlgH})$, MS (FliF), and $\mathrm{P}(\mathrm{FlgI})$; biosynthesis protein (FlhA, FlhB (2), FlhF, FliL, and Fli Q-S); motors (MotB (3), MotA (2), FliG (3), FliM, and FliN); flagellar assembly factor (FliW and FliH), cell division (BolA (2), FtsA, FtsH (2), FtsI, FtsK, FtsW, and FtsZ), and gliding motility (GldF and GldG) proteins also were registered. Strain Bairam-Ali was found to have more than ten genes for the regulation of flagellum genes transcription and for signal transduction to flagella motor. Sequences of the flagellum genes have been deposited in GenBank, accession numbers KJ701653-KJ701709.

It should be noted that the important structural element, that is, numerous groups of predicted lipoproteins (Lip), which may be either surface-exposed or located in the periplasm, is present in both saprophytic and pathogenic Leptospira species. In the strain Bairam-Ali genome, as in the genome of nonpathogenic species L. biflexa [27], genes or orthologs of the major lipoproteins LipL32 and LipL41, which are important immunodominant antigens in pathogenic Leptospira species [33,34], were not identified. Nevertheless, in the genome of Bairam-Ali, we detected six genes of LipL45 (GenBank accession numbers KJ701647-KJ701652), which are processed to a peripheral membrane associated with the outer membrane complex. According to Matsunaga et al. [35] expression of P31, derived from the carboxy terminus of LipL45, is upregulated in stationary phase cultures; thus it may have a membrane-stabilizing function. Also, in a hamster model infected with pathogenic L. kirschneri, antibodies to LipL45 [35] were produced, suggesting its involvement in pathogenesis.

Further analysis of the genome of Bairam-Ali revealed the presence of genes for more than 40 different classes of proteins, ensuring its natural resistance to a wide range of antibiotics ( $\beta$-lactams, tetracyclines, glycopeptides (vancomycin), and polymyxin); efflux system and resistance to heavy metals (Czc A-C and arsenical-resistance proteins); and possible abortive infection phage-resistance protein. The broad resistance characteristics of strain Bairam-Ali are consistent with it being a natural reservoir for storage and possible transmission of these properties to other free-living Leptospira species. Sequences of the resistome genes and their proteins have been deposited in GenBank, accession numbers KJ701605-KJ701646.

3.5. Sequence Polymorphism. To determine the place of the original strain Bairam-Ali in the Leptospira genus, we undertook phylogenetic analysis of the Leptospira groups with different pathogenicity.

Based on performed alignments, the percent nucleotide similarities of $r r s, \quad r p o B$, and MLST gene sequences of analyzed Leptospira genotypes were determined; see Supplementary Material available online at http://dx.doi.org/10.1155/2014/649034 (S1, S2, and S3). According to the obtained data, aligned sequences of $16 \mathrm{~S}$ rRNA-coding rrs gene were $1305 \mathrm{bp}$, aligned sequences of gene $r p o B$ were $493 \mathrm{bp}$, and aligned sequences of seven MLST tags ( $g l m U$-pntA-sucA-tpiA-pfkB-mreA-caiB) were $3105 \mathrm{bp}$.

Among the investigated Leptospira sequences, gene rpoB showed the highest variability, reaching $40.61 \%$. 16S rRNAcoding gene was more conservative, and general sequence variability of the rrs gene across all strains and species reached $11.52 \%$. Sequence variability of seven MLST tags reached $34.88 \%$.

Detectable intraspecific sequence polymorphism for studied loci also was different. Intraspecific differences detected by rrs were less than $1 \%$. Intraspecific differences detected by most polymorphic rpoB genes ranged from $0.61 \%$ (L. kirschneri) to $11.63 \%$ (L. borgpetersenii), with, in some cases, overlapping of intraspecific and interspecific values (S1, S2, and S3).

Notably, the intraspecific differences detected by seven MLST tags resolved all of the Leptospira genotypes and matched 3\% accepted threshold values for prokaryote species divergence $[36,37]$. The exception was $L$. weilii; interspecies differences of $L$. weilii strains revealed by seven MLST tags reached $5.77 \%$ (S1, S2, and S3).

Despite the differences in resolution ability of studied loci, all of them confirmed the unique nature of Leptospira spp. strain Bairam-Ali. rrs, rpoB, and MLST tags obtained for Bairam-Ali had low similarity with other sequences. Maximum similarity of Bairam-Ali MLST tags (69.7\%) was detected for L. interrogans (Table 3 ). At the same time, related levels of sequence similarity also characterized nonpathogenicand pathogenic Leptospira species (67.29-68.95\%) and intermediate and pathogenic Leptospira species (70.0$72.8 \%$ ). Sequence similarity in pairs of Bairam-Ali, to intermediate Leptospira species, to nonpathogenic Leptospira species, and to pathogenic Leptospira species, was 65.8$67.31 \%, 67.6-69.18 \%$, and $66.27-69.7 \%$, respectively. The level of sequence similarity between Bairam-Ali and Turneriella parva was the lowest (55.3\%), which is evidence of BairamAli belonging to the genus Leptospira.

3.6. Leptospira Phylogeny and L. spp. Bairam-Ali Location in the Leptospira Genus. The most prominent phylogenetic information was obtained through concatenated sequences of seven MLST tags. All genotypes were divided into three species groups: pathogenic, nonpathogenic, and intermediate. T. parva formed a distinct basal out-group branch.

The genetic diversity of pathogenic Leptospira reached 0.159 (MLST data), 0.006 (rrs data), and 0.121 ( $r p o B$ data). The most variable species were $L$. borgpetersenii $(0.086 \mathrm{rpoB})$ and $L$. noguchii (0.069). Despite the fact that L. interrogans was the most representative species in the analysis (120 MLST genotypes), intraspecies genetic diversity for $L$. interrogans was only 0.002 (Figure 2).

The genetic diversity of nonpathogenic Leptospira was similar to that of the pathogenic Leptospira species and 


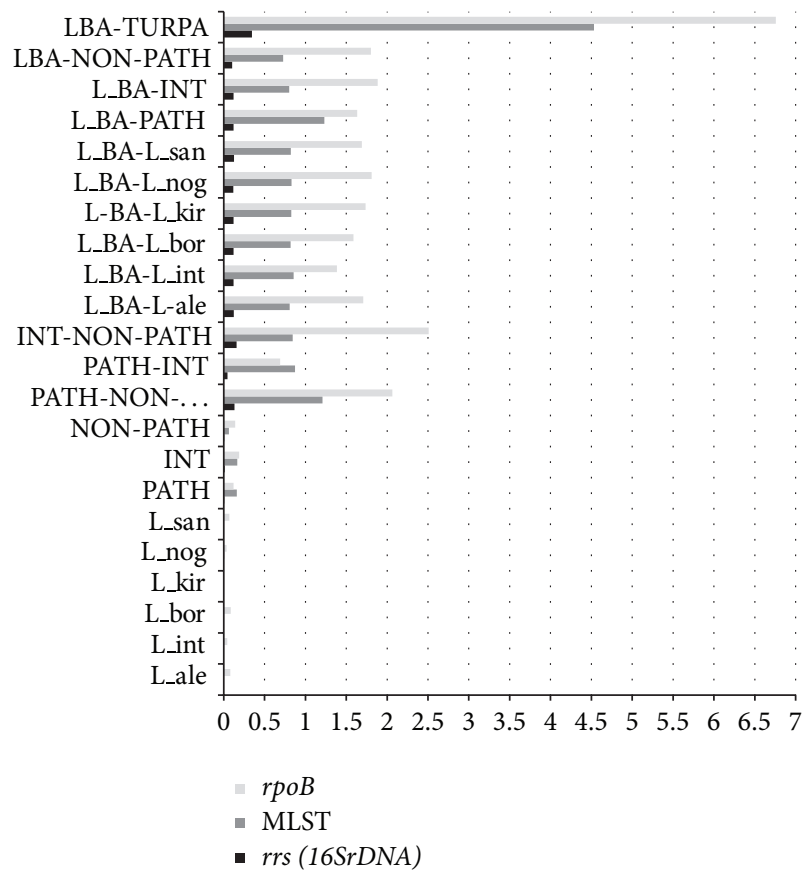

\begin{tabular}{|c|c|c|c|}
\hline \multirow{2}{*}{$\begin{array}{c}\text { Species or group } \\
\text { name }\end{array}$} & \multicolumn{3}{|c|}{ Genes } \\
\cline { 2 - 4 } & $r r s$ & MLST & $r p o B$ \\
\hline LBA-TURPA & 0.344 & 4.532 & 6.757 \\
\hline LBA-NON-PATH & 0.104 & 0.727 & 1.800 \\
\hline L_BA-INT & 0.121 & 0.803 & 1.886 \\
\hline L_BA-PATH & 0.121 & 1.232 & 1.635 \\
\hline L_BA-L_san & 0.125 & 0.821 & 1.690 \\
\hline L_BA-L_nog & 0.117 & 0.830 & 1.811 \\
\hline L-BA-L_kir & 0.121 & 0.827 & 1.737 \\
\hline L_BA-L_bor & 0.121 & 0.819 & 1.589 \\
\hline L_BA-L_int & 0.120 & 0.856 & 1.385 \\
\hline L_BA-L-ale & 0.124 & 0.807 & 1.707 \\
\hline INT-NON-PATH & 0.157 & 0.845 & 2.509 \\
\hline PATH-INT & 0.047 & 0.873 & 0.691 \\
\hline PATH-NON- & 0.133 & 1.208 & 2.063 \\
\hline NON-PATH & 0.0072 & 0.0633 & 0.1395 \\
\hline INT & 0.013 & 0.167 & 0.188 \\
\hline PATH & 0.006 & 0.159 & 0.121 \\
\hline L_san & 0.0004 & 0.0011 & 0.0684 \\
\hline L_nog & 0 & 0.0069 & 0.0356 \\
\hline L_kir & 0.0002 & 0.0023 & 0.0042 \\
\hline L_bor & 0.0008 & 0.0014 & 0.0865 \\
\hline L_int & 0 & 0.002 & 0.043 \\
\hline L_ale & 0.002 & $7,00 E-04$ & 0.081 \\
\hline & & & \\
\hline
\end{tabular}

FIGURE 2: The number of base substitutions per site from averaging over all sequence pairs within each group is shown. Analyses were conducted using the Kimura 2-parameter model.

reached 0.063 (MLST data), 0.007 ( $r r s$ data), and 0.139 ( $r p o B$ data).

Interestingly, the intermediate group Leptospira had broader genetic diversity than did the nonpathogenic or pathogenic Leptospira (0.167, MLST data; 0.013, rrs data; and 0.188 rpoB data) (Figure 2).

In pathogenic group accessions of each species, excluding L. weilii, clearly distinct phylogenetic clusters, with high bootstrap supporting values, were present.In some data sets, significant subdivision of $L$. weilii genotypes, combined with a close relationship between $L$. weilii and $L$. alexanderi, was found. Possible polyphyletic nature of $L$. weilii has been described previously, particularly in the highly divergent tpiA locus [15]. According to our data, excluding from analysis $g \operatorname{lm} U$ and $p f k B$ loci, $L$. weilii and $L$. alexanderi genotypes fall into two different but closely related subclusters. This differentiation was found also with rrs gene phylogeny (S4).

Three species in the pathogenic group, L. interrogans, L. kirschneri, and L. noguchii, formed one close genetic subgroup (BI $=99 \%$, bootstrap index). The strains of these species are often the cause of the human leptospirosis. Four species, $L$. weilii, $L$. alexanderi, $L$. borgpetersenii, and $L$. santarosai, formed another phylogenetic subgroup (BI = 98\%) (Figure 3). The strains of these species are usually isolated in natural foci. The candidate pathogenic species, L. alstoni and L. kmetyi, fell in the common big cluster of pathogenic Leptospira species. On the MLST tree, $L$. alstoni formed a sister clade to the $L$. weilii/L. alexanderi $/ L$. borgpetersenii/L. santarosai group of pathogenic Leptospira species $(\mathrm{BI}=70 \%)$, whereas $L$. kmetyi formed a basal branch
$(B I=99)($ Figure 3$)$. The levels of genetic similarity of $L$. alstoni and L. kmetyi to pathogenic Leptospira species (0.913 and 0.926$)$ were much higher than to nonpathogenic $(0.13$ and 0.09 ) or intermediate species (0.58 and 0.54 ). Our data confirm the results of previous characterization for L. alstoni on the base of 16SrDNA gene and for L. kmetyi on the base of $16 S r D N A, g y r B$, and $r p o B$ genes analysis $[2,3]$.

The single Leptospira spp. strain, Bairam-Ali, formed a separate distinct branch on dendrogram, with genetic distances comparable to those of distantly related species of different Leptospira groups. For example, differences between pathogenic and nonpathogenic, pathogenic and intermediate, and intermediate and nonpathogenic groups were 1.208, 0.873 , and 0.845 , respectively (Figure 2 ), whereas the differences between Leptospira spp. Bairam-Ali and pathogenic, intermediate, and nonpathogenic species were 1.232, 0.803, and 0.727 , respectively; this result points to significant differences between Bairam-Ali and other Leptospira species, a result that is consistent with whole genome sequencing data.

It should be noted that the comparative studies of different Leptospira groups based on the rrs gene variability, which added to the analysis the newly described saprophytic L. idonii strain Eri-1T [5] and recently approved 16S rDNA sequences of leptospires from the Peruvian Amazon, previously termed "clade C" $[38,39]$, did not change separate phylogenetic position of Leptospira spp.strain Bairam-Ali.

Thus, according to our results the Leptospira strain Bairam-Ali forms a separate phylogenetic branch of the Leptospira genus and cannot be attributed to any group of 


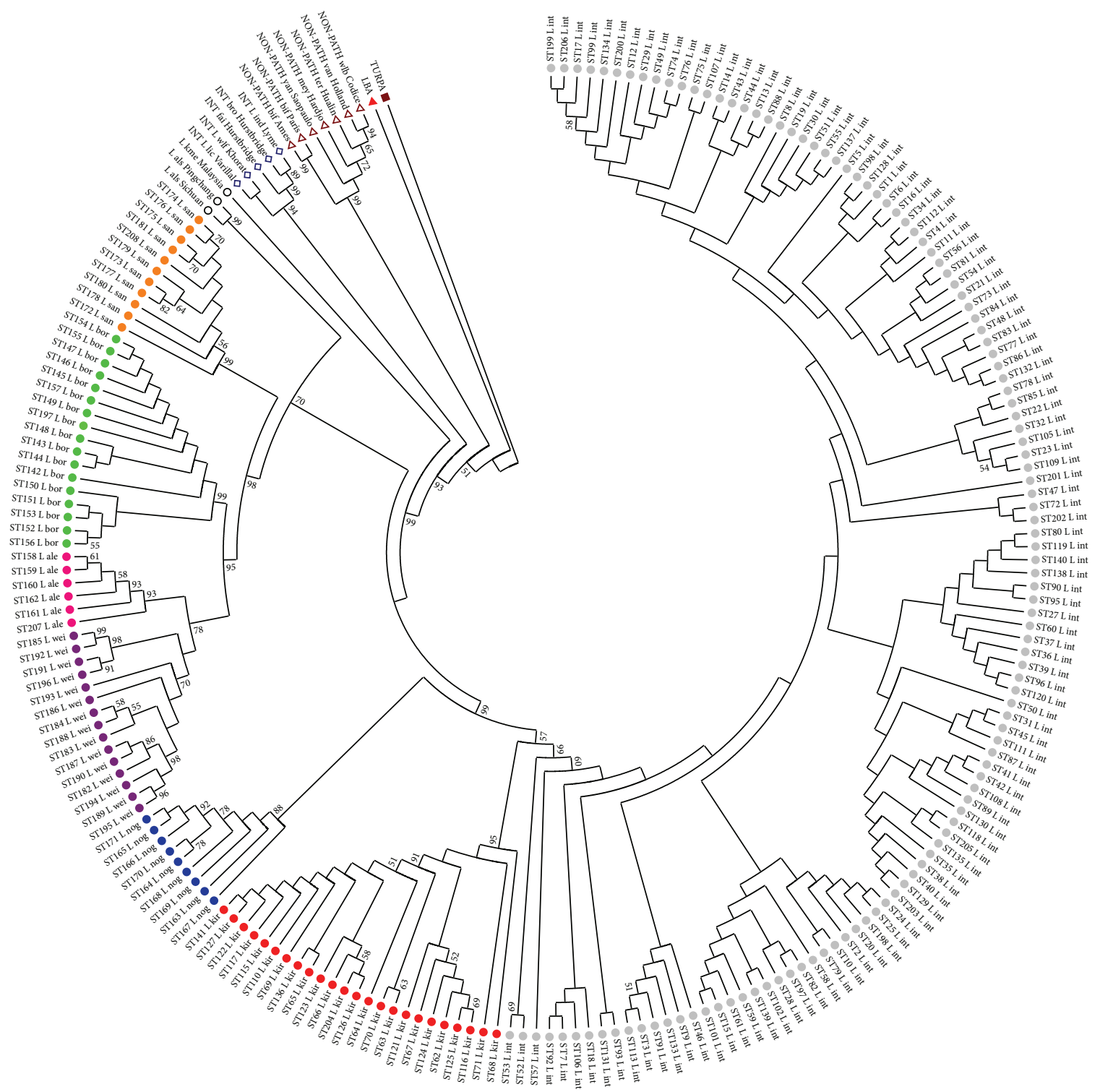

FIgUre 3: Phylogenetic tree of Leptospira species based on concatenated sequences of seven MLST loci.

pathogenic, intermediate, or saprophytic Leptospira, illustrating its uniqueness.

In conclusion, we found that the natural and anthropurgic foci supported ubiquitous pathogenic, intermediate, and nonpathogenic Leptospira species. They have circulated for a long time, interacting with maintenance and supplementary animal hosts. The relationships between the different Leptospira strains provide for horizontal gene transfer and create in the bacterial population the pool of genes important for adaptivity to various conditions. Modern molecular genetic methods are suitable for investigation of Leptospira and control of the pathogenic species, which are the causal agent of leptospirosis. Also, the taxonomic position of the new strains with unexpected properties can be founded on the base of these methods. Further investigation of the genetic diversity in the natural and anthropurgic foci is required for the identification of the Leptospira genotypes, control of the strain's transmission, and better understanding of the origin and evolution of the Leptospira species.
Abbreviations
L int: L. interrogans
L kir: L. kirschneri
L nog: L. noguchii
L wei: L. weilii
L ale: L. alexanderi
L bor: L. borgpetersenii
L san: L. santarosai
L als: L. alstoni
L kme: L. kmetyi
L lic: L. licerasiae 


$\begin{array}{ll}\text { L wlf: } & \text { L. wolffi } \\ \text { fai: } & \text { L. fainei } \\ \text { bro: } & \text { L. broomii } \\ \text { L ind: } & \text { L. inadai } \\ \text { bif: } & \text { L. biflexa } \\ \text { yan: } & \text { L. yanagawae } \\ \text { mey: } & \text { L. meyeri } \\ \text { ter: } & \text { L. terpstrae } \\ \text { van: } & \text { L. vanthielii } \\ \text { wlb: } & \text { L. wolbachii } \\ \text { LBA: } & \text { L. species Bairam-Ali } \\ \text { TURPA: } & \text { Turneriella parva } \\ \text { INT: } & \text { Intermediate species } \\ \text { NON-PATH: } & \text { Nonpathogenic species. }\end{array}$

\section{Conflict of Interests}

The authors declare that there is no conflict of interests regarding the publication of this paper.

\section{References}

[1] The List of Prokaryotic names with Standing in Nomenclature, Site founded by: J. P. Euzéby, http://www.bacterio.net/.

[2] L. Smythe, B. Adler, R. A. Hartskeerl, R. L. Galloway, C. Y. Turenne, and P. N. Levett, "Classification of Leptospira genomospecies 1, 3, 4 and 5 as Leptospira alstonii sp. nov., Leptospira vanthielii sp. nov., Leptospira terpstrae sp. nov. and Leptospira yanagawae sp. nov., respectively," International Journal of Systematic and Evolutionary Microbiology, vol. 63, no. 5, pp. 1859-1862, 2013.

[3] A. T. Slack, S. Khairani-Bejo, M. L. Symonds et al., "Leptospira kmetyi sp. nov., isolated from an environmental source in Malaysia," International Journal of Systematic and Evolutionary Microbiology, vol. 59, no. 4, pp. 705-708, 2009.

[4] G. M. Cerqueira and M. Picardeau, "A century of Leptospira strain typing," Infection, Genetics and Evolution, vol. 9, no. 5, pp. 760-768, 2009.

[5] M. Saito, S. Y. Villanueva, Y. Kawamura et al., "Leptospira idonii sp. nov., isolated from environmental water," International Journal of Systematic and Evolutionary Microbiology, vol. 63, part 7, pp. 2457-2462, 2013.

[6] Human Leptospirosis: Guidance for Diagnosis, Surveillance and Control, World Health Organization, Geneva, Switzerland, 2003, http://www.who.int/csr/don/en/WHO_CDS CDS_CSR_EPH_2002.23.pdf.

[7] Y. Arimitsu, E. Kmety, Y. Ananyina et al., "Evaluation of the one-point microcapsule agglutination test for diagnosis of leptospirosis," Bulletin of the World Health Organization, vol. 72, no. 3, pp. 395-399, 1994.

[8] Leptospira MLST database which is located at Imperial College London and is funded by the Wellcome Trust, http://leptospira.mlst.net/.

[9] L. V. Didenko, G. A. Avtandilov, N. V. Shevlyagina et al., "Biodestruction of polyurethane by Staphylococcus aureus (an investigation by SEM, TEM and FIB)," in Current Microscopy Contributions to Advances in Science and Technology, A. Méndez-Vilas, Ed., vol. 1, pp. 323-334, Formatex Research Center, Badajoz, Spain, 2012.

[10] M. Milani, D. Drobne, and F. Tatti, Atlas of FIB/SEM in Soft Materials and Life Sciences, Aracne, Rome, Italy, 2006.
[11] O. L. Voronina, M. Y. Chernukha, I. A. Shaginyan et al., "Characterization of genotypes for Burkholderia cepacia complex strains isolated from patients in hospitals of the Russian federation," Molecular Genetics, Microbiology and Virology, vol. 28, no. 2, pp. 64-73, 2013.

[12] K. Wilson, "Unit 2.4. Preparation of genomic DNA from bacteria," in Current Protocols in Molecular Biology, John Wiley and Sons, New York, NY, USA, 2001.

[13] B. La Scola, G. Baranton, A. Khamis, and D. Raoult, "Partial rpoB gene sequencing for identification of Leptospira species," FEMS Microbiology Letters, vol. 263, no. 2, pp. 142-147, 2006.

[14] J. Thaipadungpanit, V. Wuthiekanun, W. Chierakul et al., "A dominant clone of Leptospira interrogans associated with an outbreak of human leptospirosis in Thailand," PLoS Neglected Tropical Diseases, vol. 1, no. 1, article e56, 2007.

[15] S. Boonsilp, J. Thaipadungpanit, P. Amornchai et al., "A Single Multilocus Sequence Typing (MLST) scheme for seven pathogenic Leptospira species," PLoS Neglected Tropical Diseases, vol. 7, no. 1, Article ID e1954, 2013.

[16] The Main Site EMBL-EBI, European Bioinformatics Institute, http://www.ebi.ac.uk/Tools/msa/clustalw2.

[17] E. J. Feil, E. C. Holmes, D. E. Bessen et al., "Recombination within natural populations of pathogenic bacteria: short-term empirical estimates and long-term phylogenetic consequences," Proceedings of the National Academy of Sciences of the United States of America, vol. 98, no. 1, pp. 182-187, 2001.

[18] K. A. Jolley, E. J. Feil, M. S. Chan, and M. C. J. Maiden, "Sequence type analysis and recombinational tests (START)," Bioinformatics, vol. 17, no. 12, pp. 1230-1231, 2002.

[19] M. Kimura, "A simple method for estimating evolutionary rates of base substitutions through comparative studies of nucleotide sequences," Journal of Molecular Evolution, vol. 16, no. 2, pp. 111120,1980

[20] D. Posada and K. A. Crandall, "MODELTEST: testing the model of DNA substitution," Bioinformatics, vol. 14, no. 9, pp. 817-818, 1998.

[21] M. Nei and S. Kumar, Molecular Evolution and Phylogenetics, Oxford University Press, New York, NY, USA, 2000.

[22] K. Tamura, G. Stecher, D. Peterson, A. Filipski, and S. Kumar, "MEGA6: Molecular Evolutionary Genetics Analysis version 6.0," Molecular Biology and Evolution, vol. 30, no. 12, pp. 27252729, 2013.

[23] F. Gao and C.-T. Zhang, "Ori-finder: a web-based system for finding oriCs in unannotated bacterial genomes," $B M C$ Bioinformatics, vol. 9, article 79, 2008.

[24] R. K. Aziz, D. Bartels, A. Best et al., "The RAST Server: rapid annotations using subsystems technology," BMC Genomics, vol. 9, article 75, 2008.

[25] R. Overbeek, T. Begley, R. M. Butler et al., "The subsystems approach to genome annotation and its use in the project to annotate 1000 genomes," Nucleic Acids Research, vol. 33, pp. 5691-5702, 2005.

[26] M. Picardeau, "Diagnosis and epidemiology of leptospirosis," Médecine et Maladies Infectieuses, vol. 43, no. 1, pp. 1-9, 2013.

[27] M. Picardeau, D. M. Bulach, C. Bouchier et al., "Genome sequence of the saprophyte Leptospira biflexa provides insights into the evolution of Leptospira and the pathogenesis of leptospirosis," PLoS ONE, vol. 3, no. 2, Article ID e1607, 2008.

[28] S.-X. Ren, G. Fu, X.-G. Jiangk et al., "Unique physiological and pathogenic features of Leptospira interrogans revealed by wholegenome sequencing," Nature, vol. 422, no. 6934, pp. 888-893, 2003. 
[29] M. Singer and P. Berg, Genes \& Genomes: A Changing Perspective, University Science Books, 1991.

[30] A. L. T. O. Nascimento, A. I. Ko, E. A. L. Martins et al., "Comparative genomics of two Leptospira interrogans serovars reveals novel insights into physiology and pathogenesis," Journal of Bacteriology, vol. 186, no. 7, pp. 2164-2172, 2004.

[31] R. B. Bourret, N. W. Charon, A. M. Stock, and A. H. West, "Bright lights, abundant operons-fluorescence and genomic technologies advance studies of bacterial locomotion and signal transduction: review of the BLAST meeting, Cuernavaca, Mexico, 14 to 19 January 2001," Journal of Bacteriology, vol. 184, no. 1, pp. 1-17, 2002.

[32] C. Li, C. W. Wolgemuth, M. Marko, D. G. Morgan, and N. W. Charon, "Genetic analysis of spirochete flagellin proteins and their involvement in motility, filament assembly, and flagellar morphology," Journal of Bacteriology, vol. 190, no. 16, pp. 5607$5615,2008$.

[33] A. L. T. O. Nascimento, S. Verjovski-Almeida, M. A. van Sluys et al., "Genome features of Leptospira interrogans serovar Copenhageni," Brazilian Journal of Medical and Biological Research, vol. 37, no. 4, pp. 459-478, 2004.

[34] P. A. Cullen, S. J. Cordwell, D. M. Bulach, D. A. Haake, and B. Adler, "Global analysis of outer membrane proteins from Leptospira interrogans serovar Lai," Infection and Immunity, vol. 70, no. 5, pp. 2311-2318, 2002.

[35] J. Matsunaga, T. A. Young, J. K. Barnett, D. Barnett, C. A. Bolin, and D. A. Haake, "Novel 45-kilodalton leptospiral protein that is processed to a 31-kilodalton growth-phase-regulated peripheral membrane protein," Infection and Immunity, vol. 70, no. 1, pp. 323-334, 2002.

[36] E. Stackebrandt and J. Ebers, "Taxonomic parameters revisited: tarnished gold standards," Microbiology Today, vol. 33, pp. 152155, 2006.

[37] P. Vandamme and P. Dawyndt, "Classification and identification of the Burkholderia cepacia complex: past, present and future," Systematic and Applied Microbiology, vol. 34, no. 2, pp. 87-95, 2011.

[38] C. A. Ganoza, M. A. Matthias, D. Collins-Richards et al., "Determining risk for severe leptospirosis by molecular analysis of environmental surface waters for pathogenic Leptospira," PLoS Medicine, vol. 3, no. 8, article e308, 2006.

[39] J. S. Lehmann, M. A. Matthias, J. M. Vinetz, and D. E. Fouts, "Leptospiral pathogenomics," Pathogens, vol. 3, no. 2, pp. 280308, 2014. 

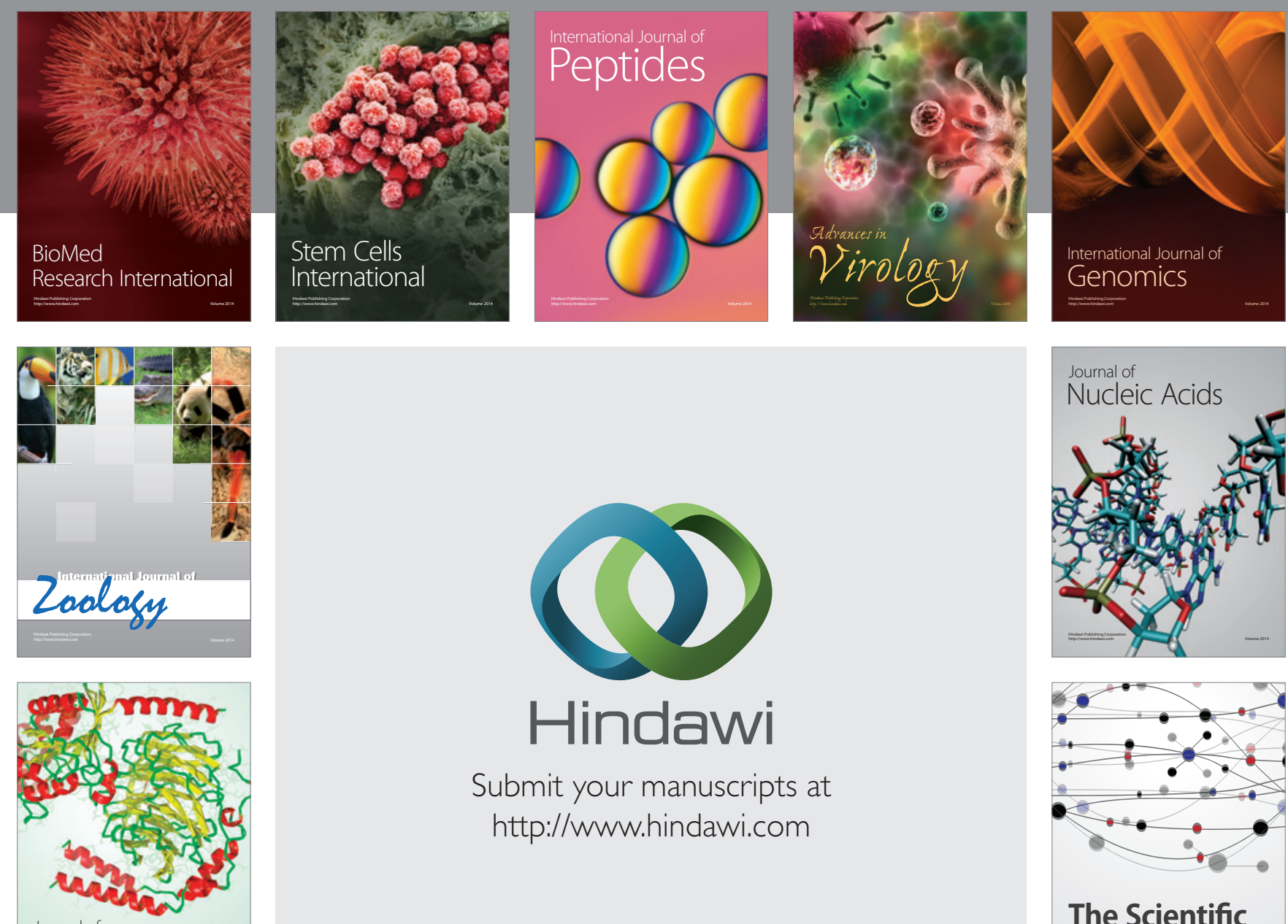

Submit your manuscripts at

http://www.hindawi.com

Journal of
Signal Transduction
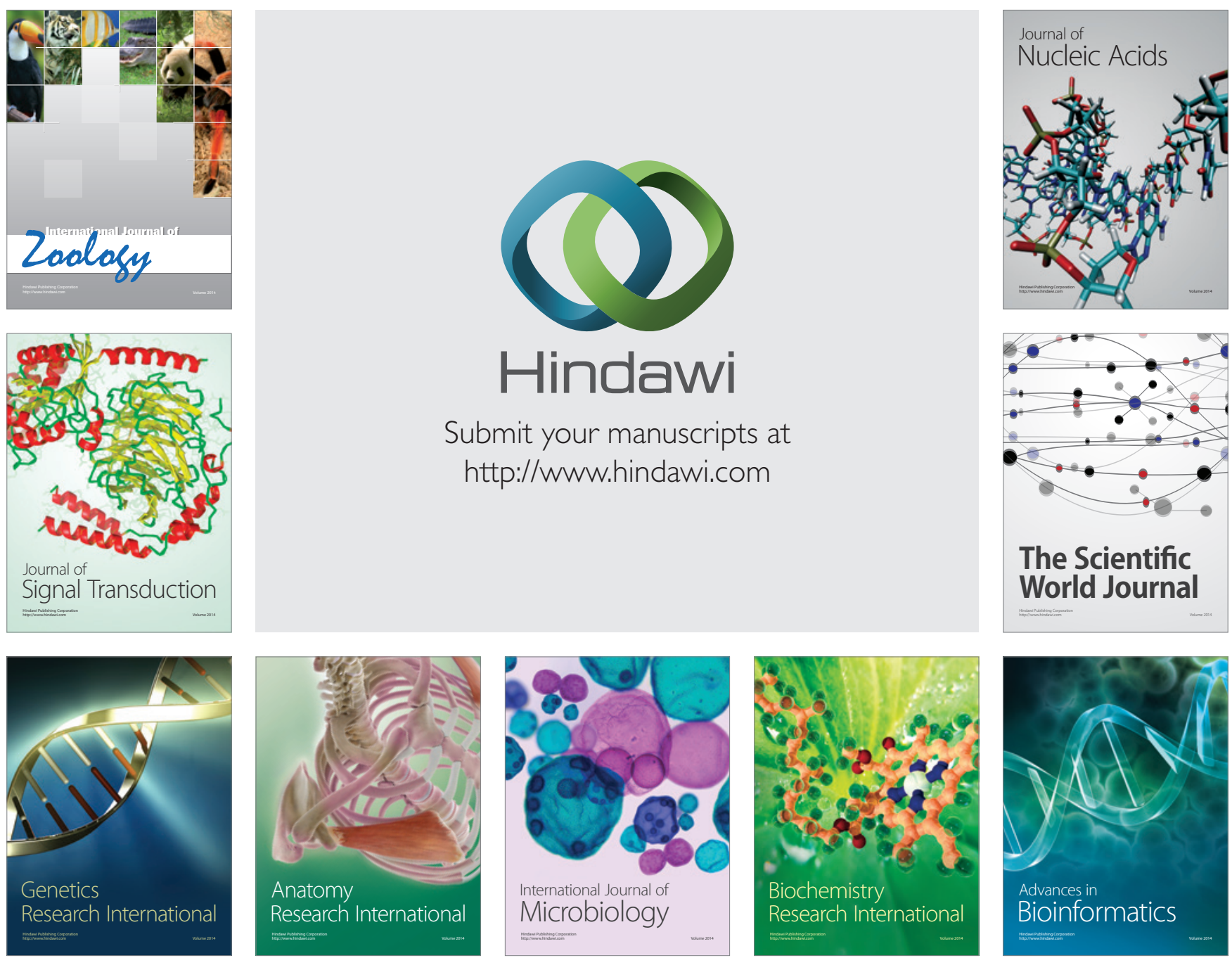

The Scientific World Journal
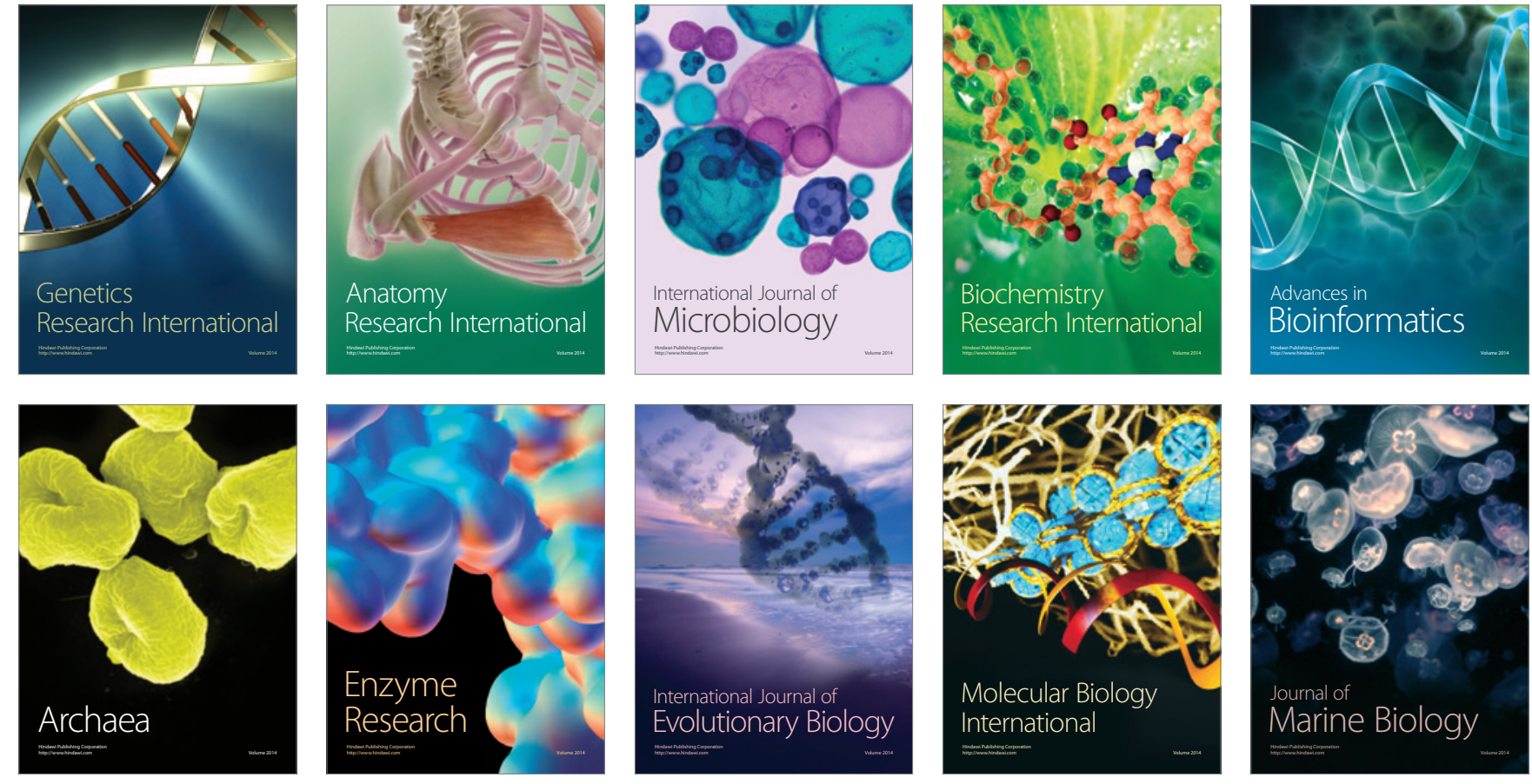